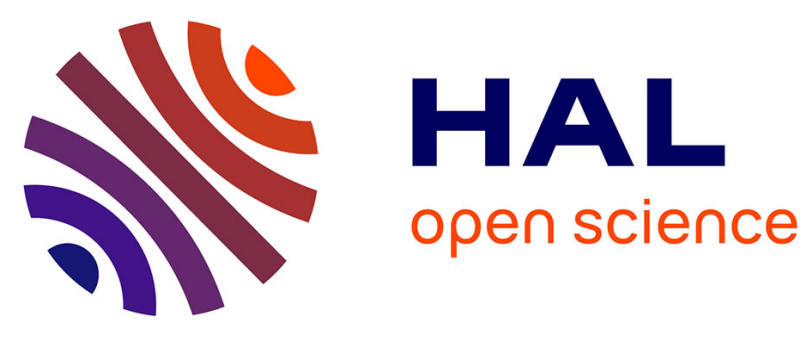

\title{
High-Pressure Synthesis, Crystal Structure and Properties of GdS2 with Thermodynamic Investigations in the Phase Diagram Gd - S
}

Carola J. Müller, Ulrich Schwarz, Peer Schmidt, Walter Schnelle, Thomas

Doert

\section{To cite this version:}

Carola J. Müller, Ulrich Schwarz, Peer Schmidt, Walter Schnelle, Thomas Doert. High-Pressure Synthesis, Crystal Structure and Properties of GdS2 with Thermodynamic Investigations in the Phase Diagram Gd - S. Journal of Inorganic and General Chemistry / Zeitschrift für anorganische und allgemeine Chemie, 2010, 636 (6), pp.947. 10.1002/zaac.201000015 . hal-00599853

\section{HAL Id: hal-00599853 https://hal.science/hal-00599853}

Submitted on 11 Jun 2011

HAL is a multi-disciplinary open access archive for the deposit and dissemination of scientific research documents, whether they are published or not. The documents may come from teaching and research institutions in France or abroad, or from public or private research centers.
L'archive ouverte pluridisciplinaire HAL, est destinée au dépôt et à la diffusion de documents scientifiques de niveau recherche, publiés ou non, émanant des établissements d'enseignement et de recherche français ou étrangers, des laboratoires publics ou privés. 


\section{Zeitschrift für Anorganische und}

Allgemeine Chemie

\section{High-Pressure Synthesis, Crystal Structure and Properties of GdS2 with Thermodynamic Investigations in the Phase Diagram Gd - S}

\begin{tabular}{|r|l|}
\hline Journal: & Zeitschrift für Anorganische und Allgemeine Chemie \\
\hline Manuscript ID: & zaac.201000015.R1 \\
\hline Wiley - Manuscript type: & Article \\
\hline Date Submitted by the & $19-$ Feb-2010 \\
\hline Complete List of Authors: & $\begin{array}{l}\text { Müller, Carola J.; Max-Planck-Institut für Chemische Physik fester } \\
\text { Stoffe } \\
\text { Schwarz, Ulrich; Max-Planck-Institut für Chemische Physik fester } \\
\text { Stoffe } \\
\text { Schmidt, Peer; Technische Universität Dresden, Fachrichtung } \\
\text { Chemie und Lebensmittelchemie } \\
\text { Schnelle, Walter; Max-Planck-Institut für Chemische Physik fester } \\
\text { Stoffe } \\
\text { Doert, Thomas; Technische Universität Dresden, Fachrichtung } \\
\text { Chemie und Lebensmittelchemie }\end{array}$ \\
\hline Keywords: & $\begin{array}{l}\text { Polysulfides, gadolinium, high-pressure synthesis, crystal structure, } \\
\text { phase diagram }\end{array}$ \\
\hline
\end{tabular}

\section{(s) ScholarONE" \\ Manuscript Central}




\title{
ARTICLE
}

DOI: 10.1002/zaac.200((will be filled in by the editorial staff))

\section{High-Pressure Synthesis, Crystal Structure and Properties of $\mathbf{G d S}_{\mathbf{2}}$ with Thermodynamic Investigations in the Phase Diagram Gd - S}

\author{
Carola J. Müller $^{[a, b]}$, Ulrich Schwarz ${ }^{[b]}$, Peer Schmidt ${ }^{[a]}$, Walter Schnelle ${ }^{[b]}$ and Thomas Doert $^{[a] *}$
}

Dedicated to Prof. Dr. Rüdiger Kniep on the Occasion of his $65^{\text {th }}$ Birthday

Keywords: Polysulfides; gadolinium; high-pressure synthesis; crystal structure; phase diagram

Gadolinium disulfide has been prepared by high-pressure synthesis at $8 \mathrm{GPa}$ and $1173 \mathrm{~K}$. It crystallizes in the monoclinic space group $P 12_{1} / a 1$ (No. 14) with lattice parameters $a=7.879(1) \quad \AA$; $b=3.936(1) \AA, c=7.926(1) \AA$ and $\beta=90.08(1)^{\circ}$. The crystal structure is a twofold superstructure of the aristotype $\mathrm{ZrSSi}$ and consists of puckered cationic $[\mathrm{GdS}]^{+}$double slabs which are sandwiched by planar sulfur sheets containing $\mathrm{S}_{2}^{2-}$ dumbbells.
The thermal decomposition of $\mathrm{GdS}_{2}$ proceeds via the sulfurdeficient polysulfides $\mathrm{GdS}_{1.9}, \mathrm{GdS}_{1.85}$ and $\mathrm{GdS}_{1.77}$ and eventually results in the sesquisulfide $\mathrm{Gd}_{2} \mathrm{~S}_{3}$.

$\mathrm{GdS}_{2}$ is a paramagnetic semiconductor which orders antiferromagnetically at $T_{\mathrm{N}}=7.7(1) \mathrm{K}$. A metamagnetic transition is observed in the magnetically ordered state. [a] Fachrichtung Chemie und Lebensmittelchemie, Technische Universität Dresden, Helmholtzstr. 10, 01062 Dresden Fax: + 35146337287

E-mail: thomas.doert@chemie.tu-dresden.de

[b] Max-Planck-Institut für Chemische Physik fester Stoffe, Nöthnitzer Str. 40, 01187 Dresden

\section{Introduction}

Polychalcogenides of rare-earth elements are known since 1908 when Biltz synthesized $\mathrm{CeS}_{2}$ [1]. The crystal structures of the polysulfides $L n X_{2-\delta}(L n=\mathrm{Y}, \mathrm{La}, \mathrm{Ce}-\mathrm{Lu} ; X=\mathrm{S}$, Se; $0 \leq \delta \leq \approx 0.2$ ) of the trivalent rare-earth metals contain puckered double slabs $\left[\mathrm{Ln}^{3+} \mathrm{X}^{2-}\right]$ which are sandwiched by planar chalcogen layers $\left[X^{\delta-}\right]$. The same atomic pattern is also found in the $\mathrm{ZrSSi}$ type which thus can be considered as the aristotype for these rare-earth metal polychalcogenides. The differences in the chalcogen content of theses compounds severely affect the electronic structure and the arrangement of the atoms in the planar layers. The number of chalcogen defects and their ordering pattern determine which kind of superstructure is formed. In recent years considerable efforts have been made to understand the phase relations between polychalcogenides of different composition and to determine their closely related superstructures (cf. [2-7]).

Two crystalline modifications for stoichiometric compounds $L n S_{2}$ and $L n S_{2}$ have been characterized. The monoclinic $\alpha$-modification (also called $\mathrm{CeSe}_{2}$ type, $P 12_{1} / a 1$, $Z=4)$ is adopted by the disulfides and diselenides from lanthanum to neodymium. $[2,6,8]$ The polytypic orthorhombic $\beta$-modification (space group Pnma, $Z=8$ ) is known for the disulfides from lanthanum to neodymium [6, 9]. Chalcogen-poorer compounds of the formula type $\operatorname{Ln} X_{1.9}$ crystallize in the $\mathrm{CeSe}_{1.9}$ type (space group $P 4_{2} / n, Z=20$ ). This structural pattern is formed for polysulfides $L n \mathrm{~S}_{1.9}$ with $L n=\mathrm{La}-\mathrm{Nd}, \mathrm{Sm}$ and $\mathrm{Gd}$ and for polyselenides $L n \mathrm{Se}_{1.9}$ with
$\mathrm{Ln}=\mathrm{La}-\mathrm{Nd}$ and $\mathrm{Sm}[3,10]$. For yttrium and the smaller lanthanide metals (terbium - lutetium) only compounds with higher chalcogen deficiency like $\operatorname{Ln} X_{1.875}$ or $\operatorname{Ln} X_{1.85}(\operatorname{Ln}=\mathrm{Y}$, $\mathrm{Gd}-\mathrm{Er}, X=\mathrm{S}, \mathrm{Se}$ ) have been synthesized [4, 5, 7, 11].

Thermoanalytical and tensimetric studies reveal that polysulfides and polyselenides $\operatorname{Ln} X_{2-\delta}$ generally decompose at elevated temperatures by a stepwise release of molecular chalcogen $X_{2}$ until the sesquichalcogenide $L_{2} X_{3}$ is finally reached $[4,12]$. Polychalcogenides of the smaller rare-earth metals have a higher decomposition pressure which is the reason that all attempts to synthesize stoichiometric disulfides or diselenides of those metals failed up to now. The increasing decomposition tendency with decreasing lattice parameters of the polychalcogenides is mainly attributed to growing anti-bonding interactions between the chalcogenide anions in the planar layers.

High-pressure synthesis is one tool to directly counteract the decomposition of rare-earth metal dichalcogenides $\operatorname{Ln} X_{2.0}$ to chalcogen defect polychalcogenides $\operatorname{Ln} X_{2-\delta}$. Earlier, Webb and Hall have prepared compounds $L n X_{2-\delta}$ by highpressure synthesis in a pressure range from 1 to $7 \mathrm{GPa}$ and temperatures up to $1700 \mathrm{~K}$ [13]. They reported a pseudotetragonal and a pseudocubic modification of the lanthanide disulfides $L n \mathrm{~S}_{2} \quad(L n=\mathrm{Gd}-\mathrm{Lu})$ and a pseudotetragonal modification of the lanthanide diselenides $\mathrm{LnSe}_{2}(\mathrm{Ln}=\mathrm{Er}-\mathrm{Lu})$. However, structure determinations on the basis of single crystal data and chemical analyses of the reaction products are missing. Later, Yanagisawa et al. succeeded to grow single crystals of $\beta-\mathrm{CeS}_{2}$ under highpressure conditions [9]. They also observed evidence for a phase transition from the monoclinic to the orthorhombic modification at $p>5.5 \mathrm{GPa}$ for the compounds $\mathrm{PrS}_{2}$ and $\mathrm{NdS}_{2}$. Raman spectroscopic investigations up to $16 \mathrm{GPa}$ at $293 \mathrm{~K}$ could not validate these results for the lanthanide disulfides with $L n=\mathrm{La}-\mathrm{Nd}$ [14]. Recently, Schleid et al. synthesized the orthorhombic modification of the disulfides $\mathrm{LnS}_{2}$ of La, Ce and Pr at ambient pressure [6]. 
In this work we present the first results of high-pressure studies on rare-earth metal polysulfides. In this contribution we focus on the synthesis of $\mathrm{GdS}_{2}$, its crystal structure and some physical properties as well as on thermodynamic investigations in the binary system gadolinium - sulfur.

\section{Results and Discussion}

\section{Synthesis}

In order to find suitable conditions for formation and crystal growth of $\mathrm{GdS}_{2}$ several reaction routes were tested at high-pressure conditions:

$$
\begin{aligned}
& \mathrm{Gd}+2 \mathrm{~S} \rightarrow \mathrm{GdS}_{2}, \\
& \mathrm{GdS}_{1.9}+0.1 \mathrm{~S} \rightarrow \mathrm{GdS}_{2}, \\
& \mathrm{Gd}_{2} \mathrm{~S}_{3}+\mathrm{S} \rightarrow 2 \mathrm{GdS}_{2}
\end{aligned}
$$

and

$$
2 \mathrm{GdCl}_{3}+3 \mathrm{~K}_{2} \mathrm{~S}_{2} \rightarrow 2 \mathrm{GdS}_{2}+6 \mathrm{KCl}+2 \mathrm{~S} .
$$

A slight excess of sulfur has been used, namely starting ratios $\mathrm{Gd}: \mathrm{S}$ of $1: 2.2$, for all reaction routes to avoid the formation of chalcogen deficient polysulfides $\mathrm{GdS}_{2-\delta}$ with $\delta>0$. Besides the reaction route (i. e. the starting material) temperature, pressure and reaction time were varied in the experiments. The target compound $\mathrm{GdS}_{2}$ is obtained at $8 \mathrm{GPa}, 1173 \mathrm{~K}$ and $3 \mathrm{~h}$ annealing time from any of the selected reactions, see equations (1) - (4). The excess of sulfur could not be detected in the powder X-ray diffraction patterns of the reaction products; it was most probably obtained as an amorphous phase. At a pressure of $3 \mathrm{GPa}$ and a similar induction heating and annealing program only $\mathrm{GdS}_{1.9}$ was obtained. At $p=15 \mathrm{GPa}$ and a temperature of $1173 \mathrm{~K} \mathrm{GdS} \mathrm{S}_{2}$ was yielded as a by-product to $\mathrm{Gd}_{2} \mathrm{~S}_{3}$. Interestingly $\mathrm{GdS}_{2}$ does also form at ambient temperature if a pressure of $8 \mathrm{GPa}$ is applied for $50 \mathrm{~h}$.

The optimization of the temperature program was done with mixtures of gadolinium sesquisulfide and sulfur at $8 \mathrm{GPa}$. Different reaction temperatures between $1373 \mathrm{~K}$ and $1823 \mathrm{~K}$ (induction heating period, usually held for $15 \mathrm{~min}$ ) followed by different annealing steps $(1173 \mathrm{~K}-1573 \mathrm{~K}$, for $3 \mathrm{~h}-43 \mathrm{~h}$ ) were tested. The sample from which the crystal for the X-ray structure determination was taken was heated to $1373 \mathrm{~K}$ in $15 \mathrm{~min}$, kept at this temperature for another 15 min and subsequently cooled to $1173 \mathrm{~K}$ during $2 \mathrm{~h}$. This temperature was then kept for $15 \mathrm{~h}$.

For reaction path (4) the alkali-metal halide can be removed by leaching with a mixture of water and ethanol but the excess sulfur still remains in the product. Adding the flux material in ratios $\mathrm{GdS}_{2}: \mathrm{CsCl}$ of $1: 6$ and $6: 1$ or changing the element ratio of $\mathrm{Gd}: \mathrm{S}$ to $1: 3$ or even $1: 6$ did not improve the crystal quality of the samples.

In short, according to the powder X-ray diffraction diagrams of the reaction products pure polycrystalline $\alpha$ $\mathrm{GdS}_{2}$ could be obtained from routes (1), (2) and (3) at $p \geq 8$ $\mathrm{GPa}$ and $973 \mathrm{~K} \leq T \leq 1573 \mathrm{~K}$. During our investigations, we found no evidence for polysulfides with higher sulfur content than $\mathrm{GdS}_{2}$ or for a phase transition of monoclinic $\alpha$ $\mathrm{GdS}_{2}$ to the orthorhombic $\beta$-modification.

The reflections in the X-ray diffraction patterns of crystalline powders synthesized in different batches exhibit strongly varying full widths at half maximum and signal/background ratios. This result is taken as an indication for marked differences in the size of the crystalline domains of various batches. Powder patterns indicating poor quality were obtained from products prepared according to the route of Webb and Hall (1) starting from the elements [13]. The solid state metathesis reaction (4) results in diffraction patterns of better quality but due to the small content of target material and the large amount of by-products this method was not considered for further experiments. The quality of samples synthesized from gadolinium sesquisulfide (2) or gadolinium polysulfide $\mathrm{GdS}_{1.9}$ (3) is similar. Since the synthesis of $\mathrm{GdS}_{1.9}$ is more difficult and time-consuming than that of $\mathrm{Gd}_{2} \mathrm{~S}_{3}$, all subsequent high-pressure experiments were performed starting from mixtures of gadolinium sesquisulfide and sulfur.

The domain size of the reaction products could be increased by annealing the samples in the temperature range of the sulfur melt at $8 \mathrm{GPa}$. This effect is attributed to an enhanced diffusion in the solid phase at high annealing temperatures which accelerates the growth of the grains. The effect that during the cooling phase bigger seed crystals grow at the expense of smaller ones is the well-known Ostwald ripening. When the temperature exceeds about $1700 \mathrm{~K}$ gadolinium disulfide decomposes to gadolinium polysulfide $\mathrm{GdS}_{1.9}$, gadolinium sesquisulfide $\mathrm{Gd}_{2} \mathrm{~S}_{3}$ and sulfur.

\section{Chemical Analysis}

The carrier gas hot extraction method did not evidence oxygen, nitrogen or hydrogen in the analyzed sample. The EDXS analysis on different parts of a sample resulted in a composition Gd: S of 1: 1.97(2) confirmed in good agreement with the assumed composition $\mathrm{GdS}_{2}$.

\section{Crystal Structure}

The results of the crystal structure analysis reveal that $\mathrm{GdS}_{2}$ adopts the $\mathrm{CeS}_{2}$ (or $\alpha-L n \mathrm{~S}_{2}$ ) type. It crystallizes in the monoclinic space group $P 12_{1} / a 1$ (No. 14). The cell parameters are $a=7.879(1) \AA, b=3.936(1) \AA, c=7.926(1)$ $\AA$ and $\beta=90.08(2)^{\circ}$. The results of the crystal structure refinement and selected interatomic distances are listed in tables $1-3{ }^{1}$

As has been discussed, the atomic pattern consists of puckered cationic $[\mathrm{GdS}]^{+}$double slabs of $\mathrm{Gd}^{3+}$ and $\mathrm{S}^{2-}$ ions (S1 in tables 2 and 3). These double slabs, which can more precisely be described with the Niggli formula ${ }_{\infty}^{2}\left[\mathrm{GdS}_{5 / 5}\right]^{+}$, are sandwiched by planar layers containing $\mathrm{S}_{2}^{2-}$ dimers accordingly. Four $\mathrm{S}$ atoms of three different $\mathrm{S}_{2}^{2-}$ anions complete the Gd coordination polyhedron, a capped slightly distorted quadratic antiprism.

\footnotetext{
${ }^{1}$ Further details concerning the structure analysis can be obtained from the Fachinformationszentrum Karlsruhe, 76344 Eggenstein-Leopoldshafen, quoting the depository number CSD-421335.
} 
Table 1: Crystallographic data and refinement parameters of $\mathrm{GdS}_{2}$.

\begin{tabular}{|c|c|}
\hline chemical composition & $\mathrm{GdS}_{2}$ \\
\hline$M_{\mathrm{r}}, \mathrm{g} / \mathrm{mol} ; F(000)$ & $221.37 ; 384$ \\
\hline temperature, $\mathrm{K}$ & $296(2)$ \\
\hline diffractometer type & Kappa CCD (Bruker-AXS) \\
\hline wavelength, $\AA$ & $\begin{array}{l}0.71073 \text { (Mo K } \alpha \text {, graphite } \\
\text { monochromator) }\end{array}$ \\
\hline crystal system & monoclinic \\
\hline space group (No.); $Z$ & $P 12_{1} / a 1(14) ; 4$ \\
\hline cell parameters & $a=7.879(1) \AA, b=3.936(1) \AA$ \\
\hline (single crystal data) & $c=7.926(1) \AA, \beta=90.08(1)^{\circ}$ \\
\hline cell volume, $\AA^{3}$ & $245.8(1)$ \\
\hline density, $\mathrm{g} / \mathrm{cm}^{3}$ & 5.98 \\
\hline absorption coefficient, $\mathrm{mm}^{-1}$ & 28.3 \\
\hline absorption correction & multi-scan (SADABS, [15]) \\
\hline$T_{\min } / T_{\max }$ & $0.2355 / 0.4650$ \\
\hline crystal size, $\mathrm{mm}^{3}$ & $0.036 \times 0.021 \times 0.004$ \\
\hline \multirow[t]{3}{*}{ measurement range } & $2.57<\Theta<35.02$ \\
\hline & $-12 \leq h, l \leq 12$ \\
\hline & $-6 \leq k \leq 6$ \\
\hline$N($ meas $) ; N($ unique $) ; N($ obs $)$ & $6223 ; 1505 ; 1396$ \\
\hline$R_{\text {int }}$ & 0.025 \\
\hline refinement method & $\begin{array}{l}\text { full-matrix least squares on } F^{2} \text {, } \\
\text { JANA2006 [16] }\end{array}$ \\
\hline restrictions / parameters & $0 / 31$ \\
\hline goodness-of-fit on $F^{2}$ & 1.02 \\
\hline$R_{1} ; \omega R_{2}$ (reflections $\left.I>3 \sigma(I)\right)$ & $0.018 ; 0.040$ \\
\hline$R_{1} ; \omega R_{2}$ (all reflections) & $0.021 ; 0.041$ \\
\hline$\Delta \rho_{\min } / \Delta \rho_{\max }, \mathrm{e}^{-3}$ & $-1.00 / 0.95$ \\
\hline \multirow[t]{3}{*}{ twin matrices } & 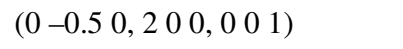 \\
\hline & $\left(\begin{array}{llllllll}-1 & 0 & 0,0 & -1 & 0,0 & 0 & 1\end{array}\right)$ \\
\hline & $\left(\begin{array}{lllllll}0 & 0.5 & 0,-2 & 0 & 0,0 & 0 & 1\end{array}\right)$ \\
\hline twin volume ratios & $0.076(4), 0.076(2)$ \\
\hline & $0.638(2), 0.210(2)$ \\
\hline
\end{tabular}

Table 2: Fractional coordinates and isotropic displacement parameters of $\mathrm{GdS}_{2}$.

\begin{tabular}{lrrrr}
\hline Atom & \multicolumn{1}{c}{$x$} & \multicolumn{1}{c}{$y$} & \multicolumn{1}{c}{$z$} & \multicolumn{1}{c}{$U_{\text {eq }}, \AA^{2}$} \\
\hline Gd & $0.12938(3)$ & $0.78670(7)$ & $0.72427(2)$ & $0.00744(4)$ \\
S1 & $0.1251(1)$ & $0.7609(2)$ & $0.3674(1)$ & $0.0078(2)$ \\
S2 & $0.1097(1)$ & $0.3399(2)$ & $-0.0031(1)$ & $0.0088(2)$ \\
\hline
\end{tabular}

As stated above, the crystal structure of monoclinic $\mathrm{GdS}_{2}$ $\left(\mathrm{CeS}_{2}\right.$ type) can be derived from the tetragonal $\mathrm{ZrSSi}$ type structure. The symmetry reduction is required due to the formation of disulfide anions in the planar chalcogen layers. The Bärnighausen tree for the three-step symmetry reduction to maximum subgroups each has been developed for isotypic $\mathrm{PrSe}_{2}$ [2]. $\mathrm{ZrSSi}$ crystallizes in space group $P 4 / \mathrm{nmm}$ (No. 129). In a first translationengleich step of index two the symmetry is reduced to the orthorhombic subgroup Pmmn (No. 59). In this t2 step the fourfold rotation along [001] is lost. The next symmetry reduction results in monoclinic space group $P 2_{1} / m$ (No. 11). In the course of this $t 2$ descent the twofold rotation along [001] is also destroyed. By doubling the $a$ axis, a klassengleich symmetry reduction of index two, the actual space group $P 12_{1} / a 1$ (No. 14) is reached. During both $t 2$ steps twinning is likely to occur and accordingly the investigated crystal turned out to be a fourfold twin. The twinning matrices resemble the loss of fourfold (and twofold) rotation axes along [001], see table 1. Pseudomerohedral twinning of $\alpha$ $\operatorname{Ln} X_{2}$ structures has frequently been found [2, 6, 8d-f]. Due to the monoclinic angle $\beta$ being close to $90^{\circ}$ and the particular relation of the lattice parameters $a \approx c \approx 2 b$ combined with reflection conditions which are inconsistent with space group symmetry, the diffraction pattern of a (multiply) twinned $\alpha-\operatorname{Ln} X_{2}$ crystal could be mistaken for pseudocubic. This may be the explanation for Webb and Hall's interpretation of the diffraction images [13]. The cell parameter 7.882(3) A of their pseusocubic phase agrees well with the cell parameter $a$ of our investigated crystal.

Table 3: $\mathrm{GdS}_{2}$. Selected interatomic distances ( $d$ in $\AA$ ).

\begin{tabular}{llll}
\hline $\mathrm{Gd}-\mathrm{S}^{\# 4}$ & $2.778(1)$ & $\mathrm{Gd}-\mathrm{S} 2^{\# 5}$ & $2.791(1)$ \\
$\mathrm{Gd}-\mathrm{S} 1^{\# 2}$ & $2.785(1)$ & $\mathrm{Gd}-\mathrm{S}^{\# 3}$ & $2.948(1)$ \\
$\mathrm{Gd}-\mathrm{S} 1$ & $2.831(1)$ & $\mathrm{Gd}-\mathrm{S}^{\# 2}$ & $3.024(1)$ \\
$\mathrm{Gd}-\mathrm{S} 1^{\# 1}$ & $2.925(1)$ & $\mathrm{Gd}-\mathrm{S}^{\# 5}$ & $3.072(1)$ \\
$\mathrm{Gd}-\mathrm{S} 1^{\# 3}$ & $3.031(1)$ & & \\
$\mathrm{S} 2-\mathrm{S} 2^{\# 8}$ & $2.140(1)$ & $\mathrm{S} 2-\mathrm{S} 2^{\# 9}$ & $2.960(1)$ \\
$\mathrm{S} 2-\mathrm{S}^{\# 7}$ & $2.960(1)$ & $\mathrm{S} 2-\mathrm{S}^{\# 10}$ & $3.186(2)$ \\
\hline
\end{tabular}

Symmetry codes:

$\# 1-x+1 / 2, y-1 / 2,-z+1 ; \# 2-x+1 / 2, y+1 / 2,-z+1 ; \# 3-x,-y+1,-z+1$;

$\# 4-x,-y+2,-z+1 ; \# 5 x, y, z+1 ; \# 6 \quad x, y+1, z+1 ; \# 7-x+1 / 2, y+1 / 2,-z$;

$\# 8-x,-y+1,-z ; \# 9-x+1 / 2, y-1 / 2,-z ; \# 10-x,-y,-z$

\section{Thermodynamic Studies}

The thermal behaviour of solid $\mathrm{GdS}_{2}$ is characterized by the incongruent thermal decomposition towards solid compounds richer in gadolinium $\left(\mathrm{GdS}_{1.9}(\mathrm{~s}), \mathrm{GdS}_{1.85}(\mathrm{~s})\right.$, etc.) and gaseous sulfur (mainly $S_{2}(g)$ ). In order to understand the decomposition mechanism and to evaluate the concrete decomposition conditions (temperature and pressure) several methods of investigation have been applied: By thermodynamic modeling of the heterogeneous equilibria the existence ranges $\left(\lg (p / b a r)\right.$ vs. $\left.T^{-1}\right)$ of all gadolinium sulfides $\mathrm{GdS}_{2-\delta}$ were estimated (Figure 2). Based on this information the phase barogram of the system $\mathrm{Gd} / \mathrm{S}$ has been established. The decomposition reactions were experimentally verified by total pressure measurement (Figure 3) and thermal analysis in combination with mass spectrometry (TG/MS).

Including the known phases of gadolinium polysulfides $\mathrm{GdS}_{2-\delta}$, the decomposition of $\mathrm{GdS}_{2}$ proceeds step-wise (5) - (8) in analogy to the incongruent decomposition of $\mathrm{PrS}_{2}$ [12a]:

$$
\begin{aligned}
& 20 \mathrm{GdS}_{2.00}(\mathrm{~s}) \rightarrow 20 \mathrm{GdS}_{1.90}(\mathrm{~s})+\mathrm{S}_{2}(\mathrm{~g}) \\
& 40 \mathrm{GdS}_{1.90}(\mathrm{~s}) \rightarrow 40 \mathrm{GdS}_{1.85}(\mathrm{~s})+\mathrm{S}_{2}(\mathrm{~g}) \\
& 25 \mathrm{GdS}_{1.85}(\mathrm{~s}) \rightarrow 25 \mathrm{GdS}_{1.77}(\mathrm{~s})+\mathrm{S}_{2}(\mathrm{~g}) \\
& 7.41 \mathrm{GdS}_{1.77}(\mathrm{~s}) \rightarrow 7.41 \mathrm{GdS}_{1.50}(\mathrm{~s})+\mathrm{S}_{2}(\mathrm{~g})
\end{aligned}
$$


The thermodynamic standard data $\Delta H_{298}^{0}\left(\mathrm{GdS}_{\mathrm{x}}\right)$ and $S_{298}^{0}\left(\mathrm{GdS}_{\mathrm{x}}\right)$ of the gadolinium sulfides were taken from the literature for $\mathrm{GdS}$ and $\mathrm{GdS}_{1.5}$ (see table 4; [17]). Unknown data for the polysulfides $\mathrm{GdS}_{2-\delta}$ were estimated in comparison with the data of the praseodymium sulfides [12a]. Applying Kirchhoff's laws and Hess' law for the thermodynamic data of the phases in reactions $(5-8)$ yielded $\Delta H_{\mathrm{R}}^{0}\left(\mathrm{GdS}_{\mathrm{x}}\right)$ and $\Delta S_{\mathrm{R}}^{0}\left(\mathrm{GdS}_{\mathrm{x}}\right)$ for the respective polysulfides. Finally the phase barogram of the system $\mathrm{Gd} / \mathrm{S}$ was developed by calculating the decomposition functions $\lg \left(p\left(\mathrm{~S}_{2}\right) /\right.$ bar $)=\mathrm{f}\left(T^{-1}\right)(9)$ of gadolinium sulfides:

$\lg \left(p\left(\mathrm{~S}_{2}\right) / \mathrm{bar}\right)=-\frac{\Delta H_{\mathrm{R}}^{0}\left(\mathrm{GdS}_{\mathrm{x}}\right)}{2.303 \cdot \mathrm{R}} \cdot \frac{1}{T}+\frac{\Delta S_{\mathrm{R}}^{0}\left(\mathrm{GdS}_{\mathrm{x}}\right)}{2.303 \cdot \mathrm{R}}$

with $\mathrm{R}$ being the universal gas constant.

The lines depicted in the barogram (Figure 2) mark the coexistence of adjacent phases, the areas in between the equilibrium lines correspondingly characterize the existence ranges of the individual phases. Following this way, the conditions for the synthesis of single phases $\mathrm{GdS}_{\mathrm{x}}$ can be deduced: The composition $\mathrm{GdS}_{2}$ is thermodynamically stable at a given temperature with a pressure above the solid line. At $T=570 \mathrm{~K}$ the decomposition pressure $p\left(\mathrm{~S}_{2}\right)$ is lower than $10^{-3}$ bar $(100 \mathrm{~Pa})$ and the compound is stable at ambient conditions. A rise in temperature causes an increased decomposition pressure: $p \approx 1$ bar $(100 \mathrm{kPa})$ at $T=870 \mathrm{~K}$ and $p \approx 10^{3}$ bar $(0.1 \mathrm{GPa})$ at $T=1270 \mathrm{~K}$. Thus, at higher reaction temperatures pressure has to be applied to counterbalance the decomposition pressure in order to obtain $\mathrm{GdS}_{2}$ under equilibrium conditions.

Table 4: Thermodynamic data for of phases in the system Gd-S.

\begin{tabular}{lrrrl}
\hline Phase & $\begin{array}{c}\Delta H_{298}^{0} / \\
\mathrm{kJ} \cdot \mathrm{mol}^{-1}\end{array}$ & $\begin{array}{c}S_{298}^{0} / \\
\mathrm{J} \cdot \mathrm{mol}^{-1} \cdot \mathrm{K}^{-1}\end{array}$ & $\begin{array}{c}C_{\mathrm{p}} / \\
\mathrm{J} \cdot \mathrm{mol}^{-1} \cdot \mathrm{K}^{-1}\end{array}$ & Reference \\
\hline $\mathrm{Gd}$ & 0 & 67.9 & 32.8 & {$[17]$} \\
$\mathrm{GdS}$ & -460.0 & 77.4 & 58.0 & {$[17]$} \\
$\mathrm{Gd}_{2} \mathrm{~S}_{3}$ & -1205.0 & 187.0 & 141.0 & {$[17]$} \\
$\mathrm{GdS}_{1.77}$ & -612.0 & 101.6 & 77.3 & \\
$\mathrm{GdS}_{1.85}$ & -612.9 & 104.2 & 79.3 & {$[17]$} \\
$\mathrm{GdS}_{1.90}$ & -613.4 & 105.8 & 80.5 & \\
$\mathrm{GdS}_{2.00}$ & -613.9 & 108.8 & 83.0 & \\
$\mathrm{~S}_{2(\mathrm{~g})}$ & 0 & 32.0 & 25.0 & {$[17]$} \\
\hline
\end{tabular}

\section{Insert Figure 2 here}

The phase barogram of $\mathrm{GdS}_{2}$ has been experimentally verified using total pressure measurements with a Bourdon manometer (see experimental section). The decomposition reaction starts at temperatures above $570 \mathrm{~K}$ with a pressure of $10^{-3}$ bar $(100 \mathrm{~Pa})$, and follows the course of the equilibrium line (Figure 3 ). With an average sample mass of about $75 \mathrm{mg}$, the decomposition of $\mathrm{GdS}_{2}$ is completed at about $670 \mathrm{~K}$ and a drift towards the decomposition line of $\mathrm{GdS}_{1.9}$ is observed The course of measured decomposition pressures of $\mathrm{GdS}_{2}$ and $\mathrm{GdS}_{1.9}$ confirms the equilibrium conditions calculated in the phase barogram. As a conclusion, $\mathrm{GdS}_{2}$ is stable at temperatures below $670 \mathrm{~K}$ under its own decomposition pressure, while the phase is unstable at temperatures above $670 \mathrm{~K}$ without compensation of the sulfur pressure.

\section{Insert Figure 3 here}

Finally, the decomposition of $\mathrm{GdS}_{2}$ was studied at ambient pressure using thermogravimetry in an argon atmosphere. In accordance with the phase barogram, the thermal degradation of $\mathrm{GdS}_{2}$ starts at $T \approx 470 \mathrm{~K}$ and proceeds via four distinct steps, namely $\mathrm{GdS}_{1.9}, \mathrm{GdS}_{1.85}$, and $\mathrm{GdS}_{1.77}$, towards $\mathrm{Gd}_{2} \mathrm{~S}_{3}$. The constant final mass is reached at $T \approx 1020 \mathrm{~K}$; the solid product was identified by powder $\mathrm{X}$ ray diffraction as a mixture of $A$-type $\mathrm{Gd}_{2} \mathrm{~S}_{3}$ [18a] and $C$ type $\mathrm{Gd}_{2} \mathrm{~S}_{3}$ [18b]. The gaseous decomposition products were analyzed by mass spectrometry: $S_{2}(m / z=64)$ was identified as the main species. At lower temperatures the species $S_{8}(g)$, $\mathrm{S}_{6}(\mathrm{~g})$ and $\mathrm{S}_{4}(\mathrm{~g})$ were detected in minor amounts as well. Nevertheless the general decomposition mechanism of $\mathrm{GdS}_{2}$ and $\mathrm{GdS}_{2-\delta}$ according the equilibrium reactions $(5-8)$ is confirmed.

The release of sulfur has only consequences for the planar chalcogen layers of the polysulfide. In $\mathrm{GdS}_{2}$ the planar sulfide layers consists of $\mathrm{S}_{2}^{2-}$ dumbbells only while in $\mathrm{GdS}_{1.9}$ dimeric $\mathrm{S}_{2}^{2-}$ anions, single $\mathrm{S}^{2-}$ anions and vacancies can be found in the layers [3]. The structure of $\mathrm{GdS}_{1.85}$ is not yet known, it might either adopt the modulated $\operatorname{PrSe}_{1.85}$ type [7] or a defect variant of the $\mathrm{Gd}_{8} \mathrm{Se}_{15}$ structure, a 24-fold superstructure of the ZrSSi type [5]. The higher chalcogen deficiency is reflected in a higher amount of vacancies and single $X^{2-}$ anions in the respective chalcogen layers in both structure patterns. The formation of chalcogen deficient polychalcogenides by depletion of sulfur comes to an end with $\mathrm{GdS}_{1.77}$ before the ordinary sulfide $\mathrm{Gd}_{2} \mathrm{~S}_{3}$ is formed. No meaningful structure model has been established for $\operatorname{LnX} X_{1.77}$ compounds yet although indications for the existence of phases of this approximate composition were found during several tensimetric studies $[4,12]$.

\section{Physical Properties}

The temperature dependence of the resistivity $\rho(T)$ could be followed down to $63 \mathrm{~K}$ where the resistance reached the upper limit of our experimental setup. The decrease in direction of increasing temperatures (Figure 4) indicates that $\mathrm{GdS}_{2}$ is semiconducting. A lower estimate of $0.36 \mathrm{eV}$ for the fundamental gap at room temperature may be obtained from the temperature dependence of $\rho(T)$. The high resistivity of approximately $0.13 \Omega \mathrm{m}$ at $300 \mathrm{~K}$ indicates that the polycrystalline sample material has only a small concentration of point defects. This finding and the semiconducting properties of $\mathrm{GdS}_{2}$ indicate a valence compound in which the electrons of the anionic partial structure are located in bonds or free electron pairs as reflected by the description $\left[\mathrm{Gd}^{3+} \mathrm{S}^{2-}\right]_{2}\left[\mathrm{~S}_{2}^{2-}\right]$ with completely filled valence shells of the sulfur ions. 


\section{Conclusions}

Gadolinium disulfide was obtained by high-pressure synthesis using different starting materials. $\mathrm{GdS}_{2}$ adopts the monoclinic $\mathrm{CeSe}_{2}$ type, a twofold superstructure of the $\mathrm{ZrSSi}$ type. $\mathrm{GdS}_{2}$ is a paramagnetic semiconductor containing $\mathrm{Gd}^{3+}$ and exhibits antiferromagnetic order at $T_{\mathrm{N}}=7.7(1) \mathrm{K}$. The formation of this disulfide is achieved by counterbalancing its decomposition pressure of, e.g., $p \approx 10^{3}$ bar $(0.1 \mathrm{GPa})$ at $T=1270 \mathrm{~K}$. A synthesis of $\mathrm{GdS}_{2}$ at ambient pressure thus fails either because of insufficient reactivity at lower temperatures (say below $\approx 850 \mathrm{~K}$ ) or because the decomposition pressure is exceeded at elevated temperatures. It can be assumed that the syntheses of further, yet unknown rare-earth metal polysulfides under high-pressure conditions will be possible. The exploration of appropriate reaction conditions, especially for crystal growth, remains, however, still a challenge.

\section{Experimental Section}

Preparation and sample handling was performed under argon atmosphere in glove boxes (MBraun, $\mathrm{H}_{2} \mathrm{O}<1 \mathrm{ppm}, \mathrm{O}_{2}<1 \mathrm{ppm}$ ).

$\mathrm{Gd}_{2} \mathrm{~S}_{3}$ was synthesized from a mixture of gadolinium (99.9\%, Treibacher) and sulfur (99.95\%, Alfa Aesar) in a molar ratio of $2: 3$ (10). The elements were filled in silica ampoules with glassy carbon crucibles which were sealed under dynamic vacuum $\left(p<10^{-4}\right.$ mbar). The ampoules were placed in a muffle furnace and heated to $1273 \mathrm{~K}$ in $24 \mathrm{~h}$. After annealing at this temperature for $72 \mathrm{~h}$ the ampoules were cooled to $298 \mathrm{~K}$ in $24 \mathrm{~h}$.

$$
2 \mathrm{Gd}+{ }^{3} / 2 \mathrm{~S}_{2} \rightarrow \mathrm{Gd}_{2} \mathrm{~S}_{3}
$$

The sesquisulfide was obtained as a mixture of the $A$-type (space group Pnma, [18a]) and $C$-type (defect $\mathrm{Th}_{3} \mathrm{O}_{4}$ type, $I \overline{4} 3 d$, [18b]) under these conditions.

For gadolinium polysulfide $\mathrm{GdS}_{1.9}$ a solid state metathesis reaction was used [3], see equation (11). $\mathrm{GdCl}_{3}$ (99.9\%, Strem) and $\mathrm{Na}_{2} \mathrm{~S}_{2}$ were mixed and filled in silica ampoules with glassy carbon crucibles. After sealing under dynamic vacuum the ampoules were annealed 9 days at $1023 \mathrm{~K}$ and afterwards cooled to room temperature with a rate of $3 \mathrm{~K} / \mathrm{h}$.

$2 \mathrm{GdCl}_{3}+3 \mathrm{Na}_{2} \mathrm{~S}_{2} \rightarrow 2 \mathrm{GdS}_{1.9}+6 \mathrm{NaCl}+2.2 \mathrm{~S}$

The excessive sulfur was eliminated by sublimation $(623 \mathrm{~K} \rightarrow 298$ $\mathrm{K})$ in a horizontal tube furnace. The sodium chloride which is formed during the reaction acts as flux medium; it was removed with a mixture of water and ethanol $(1: 1)$.

High-pressure syntheses were performed with a $1000 \mathrm{t}$ hydraulic press (Fa. Voggenreiter) at $8(0.8) \mathrm{GPa}$ and temperatures between 293(15) K and 1373(69) K. For force redistribution and pressure generation a Walker-type module was used with $\mathrm{MgO}$ (doped with $5 \% \mathrm{Cr}_{2} \mathrm{O}_{3}$ ) octahedra of edge length $18 \mathrm{~mm}$ [19]. Starting materials were filled under argon into crucibles machined of hexagonal boron nitride. Stepped graphite tubes were used for heating [20]. No reaction between starting material or products and crucible material has been observed.

$X$-Ray diffraction experiments on powder samples were performed in transmission arrangements on a Huber Image Plate system G670 with Co $K \alpha_{1}$ radiation. The program package WinXPow was applied for the interpretation of the powder diffractograms [21]. Single crystal experiments were performed on a Bruker Kappa CCD diffractometer with Mo $K \alpha$ radiation using the software package SAINT [22]. Structure images have been realized with DIAMOND [23].

Chemical analysis for hydrogen, nitrogen and oxygen was performed with the carrier gas hot extraction method on a LECO TCH 600. For EDXS analysis the sample were embedded with Technovit 550, ground with silicon carbide paper and polished with diamond suspensions. The EDXS analysis was performed with a Philips $\mathrm{XL}_{30}$ with $\mathrm{LaB}_{6}$ cathode and a $\mathrm{Si}(\mathrm{Li})$ detector.

Thermogravimetric measurements were carried out with corundum crucibles in an analyzer STA 409 CD from NETZSCH skimmer-coupled to a mass spectrometer (Quadstar 422, Pfeiffer). Measurements were performed in the temperature range from $T=298 \mathrm{~K}$ to $1470 \mathrm{~K}$ with a heating rate of $10 \mathrm{~K} \cdot \mathrm{min}^{-1}$ in $\operatorname{argon}$ atmosphere. Buoyancy was corrected by measuring the empty crucible before the experiment. The particular decomposition temperature was determined at the onset of the corresponding weight loss.

Total pressure measurements were carried out in a Bourdon manometer of silica glass [24]. Measuring points have been collected every $20 \mathrm{~K}$ in the temperature range from $T=520 \mathrm{~K}$ to $820 \mathrm{~K}$.

Estimation of standard data: The standard enthalpies of formation of phases $\mathrm{GdS}_{2-\delta}$ have been estimated based on the values of analogous praseodymium sulfides. As for all unknown standard entropies of formation and functions of heat capacity presented in this work, approximations of $S_{298}^{0}$ and $C_{\mathrm{p}}(T)$ have 
been performed according to the Neumann-Kopp rule as the stoichiometric sum of the particular values of $\mathrm{Gd}_{2} \mathrm{~S}_{3}$ and $\mathrm{S}$.

Physical properties of $\mathrm{GdS}_{2}$ were measured on a polycrystalline piece of the same batch from which the crystal for structure determination and material for TG/MS analysis was taken. The electrical resistance was measured by the four-point method using direct current in the temperature range $4-320 \mathrm{~K}$. The magnetization was determined in magnetic fields $\mu_{0} H$ between 0.01 $\mathrm{T}$ and $7 \mathrm{~T}$ and temperatures between $1.8 \mathrm{~K}$ and $400 \mathrm{~K}$ in a SQUID magnetometer (MPMS XL-7, Quantum Design).

\section{Acknowledgments}

The authors thank Susann Leipe for supporting high-pressure synthesis, Dr. Stefan Hoffmann and Susann Scharsach for the TG/MS measurements, Gudrun Kadner for the measurement of vapor pressure, and Dr. Marcus Schmidt as well as Prof. Dr. Juri Grin for helpful discussions. The competence groups Analytics and Structure at the MPI CPfS are gratefully acknowledged as well as financial support by the Deutsche Forschungsgemeinschaft.

[1] W. Biltz, Berichte d. Dt. Chem. Gesellschaft 1908, 41, 33413350 .

[2] Th. Doert, Chr. Graf, Z. Anorg. Allg. Chem. 2005, 631, $1101-1106$.

[3] Th. Doert, Chr. Graf, P. Lauxmann, Th. Schleid, Z. Anorg. Allg. Chem. 2007, 633, 2719-2724.

[4] Th. Doert, Chr. Graf, P. Schmidt, I. G. Vasilieva, P. Simon, W. Carrillo-Cabrera; J. Solid State Chem. 2007, 180, 496509.

[5] Th. Doert, E. Dashjav, B. P. T. Fokwa, Z. Anorg. Allg. Chem. 2007, 633, 261-273.

[6] Th. Schleid, P. Lauxmann, Chr. Graf, Chr. Bartsch, Th. Doert, Z. Naturforsch. 2009, 64b, 189-196.

[7] Chr. Graf, Th. Doert, Z. Kristallogr. 2009, 224, 568-579.

[8] a) J. P. Marçon, R. Pascard, C.R. Acad. Sci. Paris, Ser. C 1968, 266, 270-272; b) S. Bénazeth, D. Carré, M. Guittard, J, Flahaut, C.R. Acad. Sci. Paris, Ser. C 1975, 280, 1021-1024 c) S. Bénazeth, M. Guittard, J, Flahaut, J. Solid State Chem. 1981, 37, 44-48; d) S. Bénazeth, D. Carré, P. Laruelle, Acta Crystallogr. 1982, B38, 33-37; e) S. Bénazeth, D. Carré, P. Laruelle, Acta Crystallogr. 1982, B38, 37-39; f) R. Tamazyan, H. Arnold, V. N. Molchanov, G. M. Kuzmicheva, I. G. Vasilieva, Z. Kristallogr. 2000, 215, 272-277.

[9] a) Y. Yanagisawa, S. Kume, Mater. Res. Bull. 1973, 8, 12411246; b) Y. Yanagisawa, F. Kanamaru, S. Kume, Acta Crystallogr. 1979, B35, 137-139; c) Y. Yanagisawa, S. Kume, Mater. Res. Bull. 1986, 21, 379-385.

[10] a) R. Tamazyan, H. Arnold, V. N. Molchanov, G. M. Kuzmicheva, I. G. Vasilieva, Z. Kristallogr. 2000, 215, 346351; b) P. Plambeck-Fischer, W. Abriel, W. Urland, J. Solid State Chem. 1989, 78, 164-169; c) W. Urland, P. PlambeckFischer, M. Grupe, Z. Naturforsch. B. 1989, 44, 261-264; d) M. Gruppe, W. Urland, J. Less Common Met. 1991, 170, 271-275; e) E. Dashjav, Th. Doert, P. Böttcher, H. Mattausch, O. Oeckler, Z. Kristallogr. NCS 2000, 215, 337-338.

[11] a) A. van der Lee, L. M. Hoistad, M. Evain, B. J. Foran, S Lee, Chem. Mater. 1997 9, 218-226.; b) R. Tamazyan, S. van Smaalen, I. G. Vasilyeva, H. Arnold, Acta Crystallogr. 2003 B59, 709-719.

[12] a) Chr. Graf, P. Schmidt, Th. Doert, unpublished results; b) T. P. Chusova, L. N. Zelenina, I. G. Vasilyeva, Chr. Graf, Th. Doert, J. Alloys Comp. 2008 452, 94-98.

[13] a) A. W. Webb, H. T. Hall, Inorg. Chem. 1970, 9, 843-847; b) A. W. Webb, H. T. Hall, Inorg. Chem. 1970, 9, 1084 1090 .
[14] a) O. Degtyareva, E. Gregoryanz, M. Somayazulu, P. Dera, H. K. Mao, R. J. Hemley, Nat. Mater. 2005, 4, 152-155; b) O. Degtyareva, E. R. Hernandez, J. Serrano, M. Somayazulu, H. K. Mao, E. Gregoryanz, R. J. Hemley, J. Chem. Phys.. 2007, 126,084503

[15] SADABS, G. M. Sheldrick, University of Göttingen, Germany, 2004.

[16] JANA2006. The crystallographic computing system, V. Petricek, M. Dusek, L. Palatinus, Institute of Physics, Praha, Czech Republic, 2009.

[17] a) O. Knacke, K. Kubaschewski, K. Hesselmann, Thermochemical Properties of Inorganic Substances, Springer, Berlin, Heidelberg, New York, 1991; b) K.C. Mills, Thermodynamic Data for Inorganic Sulfides, Selenides and Tellurides, Butterworths, London, 1974; c) I. G. Vasilieva, Neorg. Mater. 1985, 21, 1043-1045.

[18] a) A. W. Sleight, C. T. Prewitt, Inorg. Chem. 1968, 7, 10901093; b) Th. Schleid, F. A. Weber, Z. Anorg. Allg. Chem. 1998, 624, 557-558.

[19] D. Walker, M. A. Carpenter, C. M. Hitch, Am. Mineral. 1990, $75,1020-1028$

[20] M. J. Walter, Y. Thibault, K. Wei, R. W. Luth, Can. J. Phys. 1995, 73, 273-286.

[21] WinXPow. Powder diffraction software, Stoe \& Cie., Darmstadt, Germany, 1999.

[22] SAINT. Bruker AXS Inc.; Madison, Wisconsin, USA, 2008.

[23] DIAMOND 3, Crystal and molecular structure visualization, Crystal Impact, GbR, Bonn, 2009.

[24] H. Oppermann, O. Schneider, E. Wittig, Chem. Techn. 1966, $18,433$.

Received: ((will be filled in by the editorial staff)) Published online: ((will be filled in by the editorial staff) 
1

2

3

4

5

6

7

8

9

10

11

12

13

14

15

16

17

18

19

20

21

\section{Figure captions:}

Figure 1: Crystal structure of $\mathrm{GdS}_{2}$, central projection of the unit cell along [010] (left) and dumbbell pattern of disulfide anions (right); ellipsoids at a 99.9\% probability level.

Figure 2: Phase barogram of the system $\mathrm{Gd}-\mathrm{S}$ calculated according to equation (9) using the standard data of the polysulfide phases (table 4).

Figure 3: Measurement of the decomposition pressure of $\mathrm{GdS}_{2}$ and $\mathrm{GdS}_{1.85}$ [17] in comparison to calculation of the decomposition equilibria.

Figure 4: Electrical resisitivity $\rho(T)$ of polycrystalline $\mathrm{GdS}_{2}$.

Figure 5: Reciprocal magnetic susceptibility $1 / \chi$ of $\mathrm{GdS}_{2}$ as function of temperature $T$ in two different external fields $\mu_{0} H(0.1 \mathrm{~T}$ and $1 \mathrm{~T})$. Upper inset: magnetic susceptibility $\chi(T)$ for $\mu_{0} H=0.01 \mathrm{~T}$ at low temperatures. Lower inset: magnetic susceptibility $\chi$ as function of external field $\mu_{0} H$ for $T=1.8 \mathrm{~K}$. See text for discussion. 


\section{Page 9 of 13}
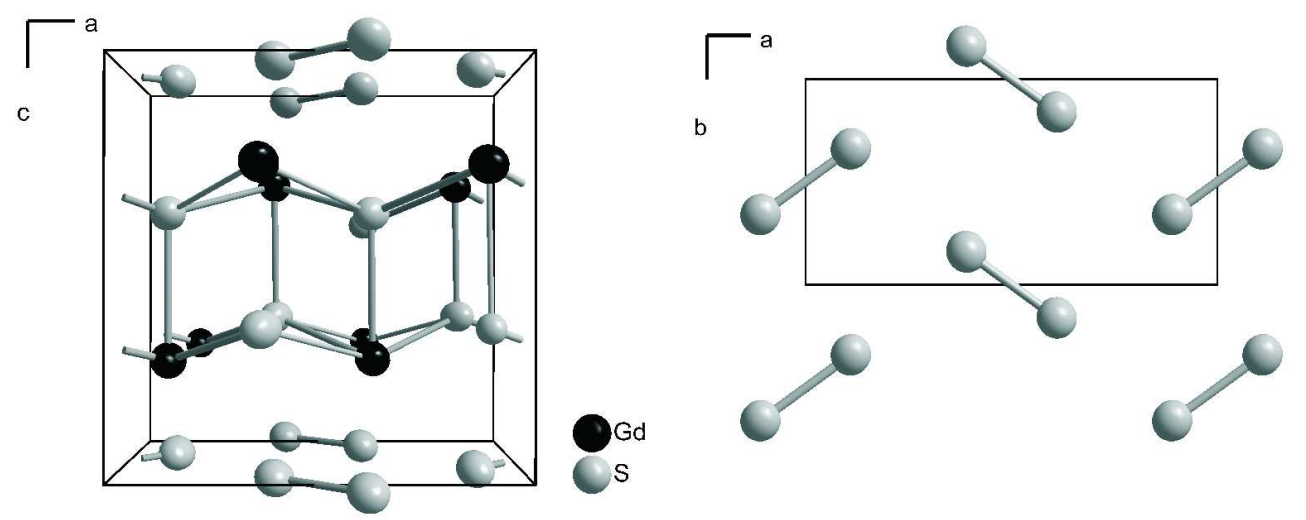

Figure 1: Crystal structure of $\mathrm{GdS}_{2}$, central projection of the unit cell along [010] (left) and dumbbell pattern of disulfide anions (right); ellipsoids at a $99.9 \%$ probability level. $79 \times 33 \mathrm{~mm}(500 \times 500 \mathrm{DPI})$ 


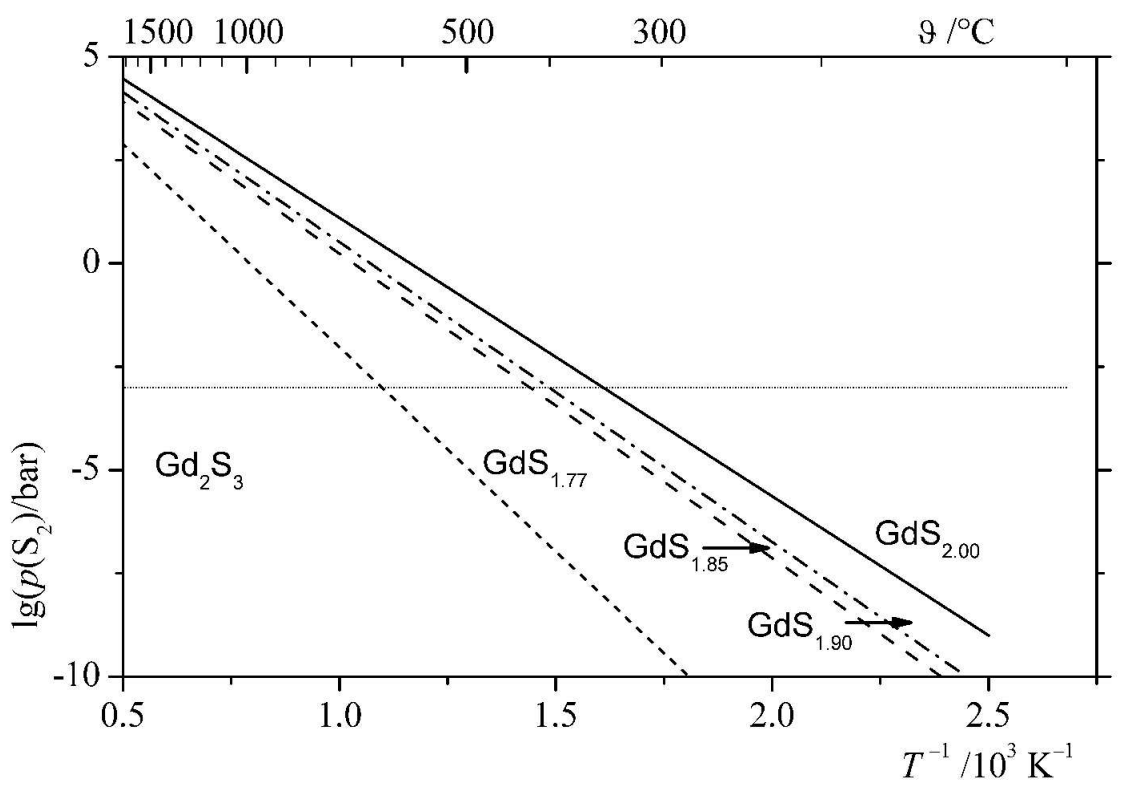

Figure 2: Phase barogram of the system Gd - S calculated according to equation (9) using the standard data of the polysulfide phases (table 4). $275 \times 197 \mathrm{~mm}(600 \times 600 \mathrm{DPI})$ 


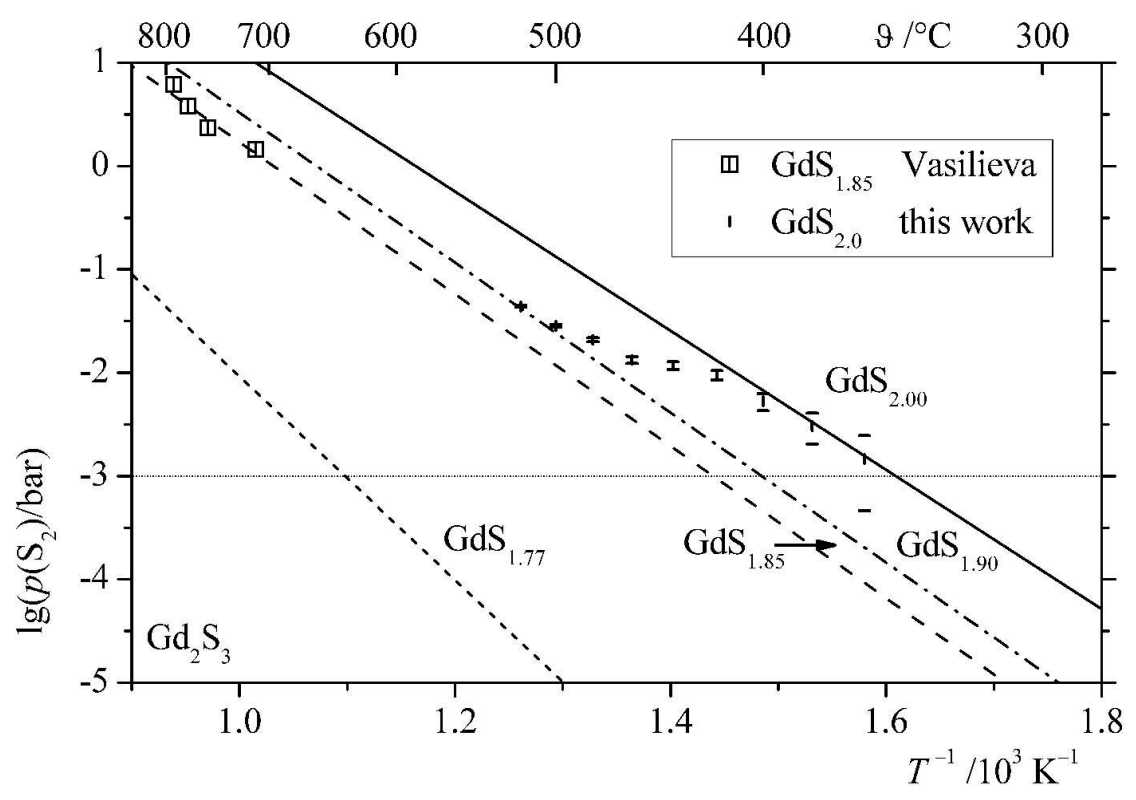

Figure 3: Measurement of the decomposition pressure of $\mathrm{GdS}_{2}$ and $\mathrm{GdS}_{1.85}$ [17] in comparison to calculation of the decomposition equilibria. $276 \times 197 \mathrm{~mm}(600 \times 600 \mathrm{DPI})$ 


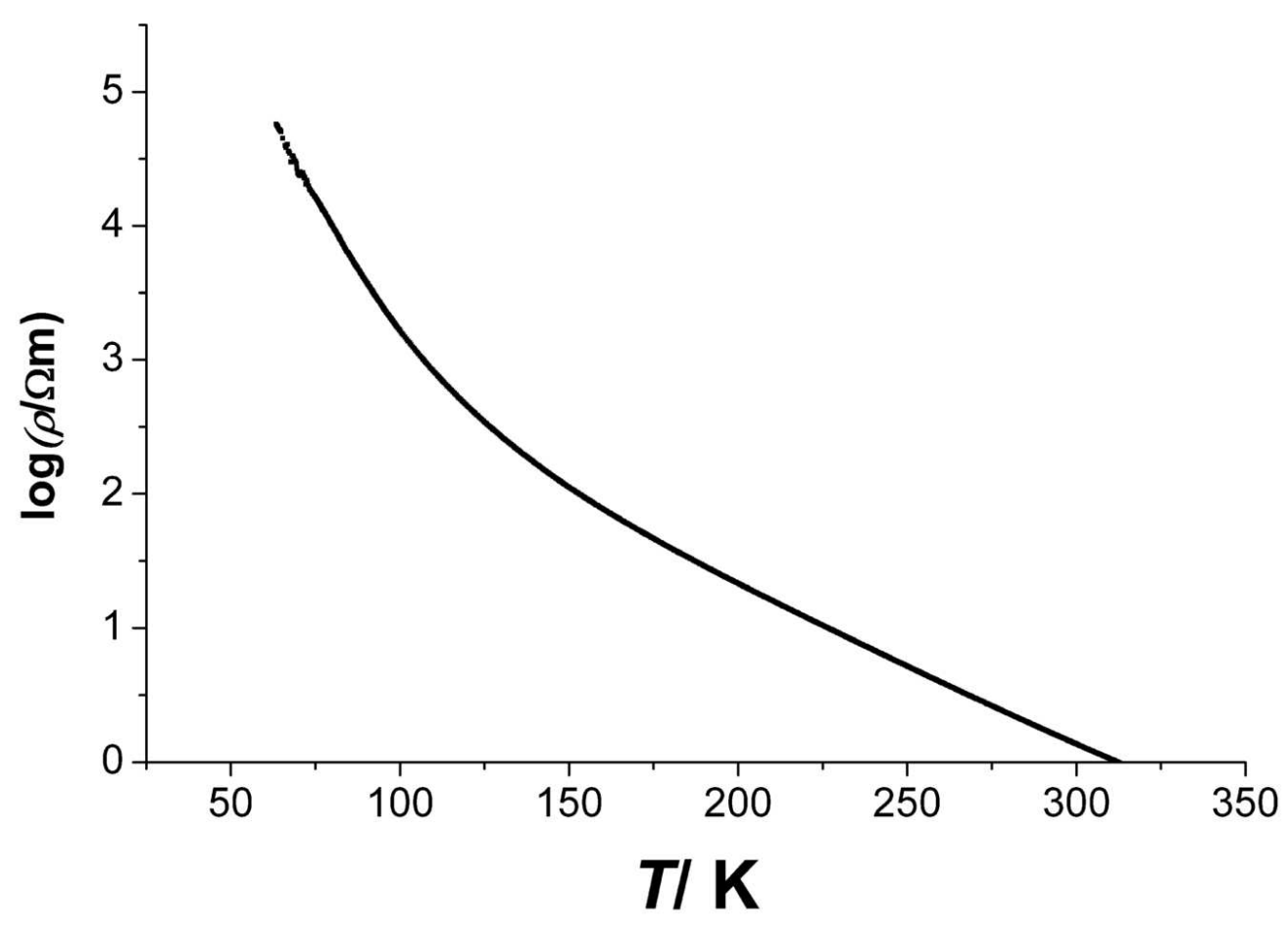

Figure 4: Electrical resisitivity $\rho(T)$ of polycrystalline $\mathrm{GdS}_{2}$. $56 \times 40 \mathrm{~mm}(600 \times 600 \mathrm{DPI})$ 


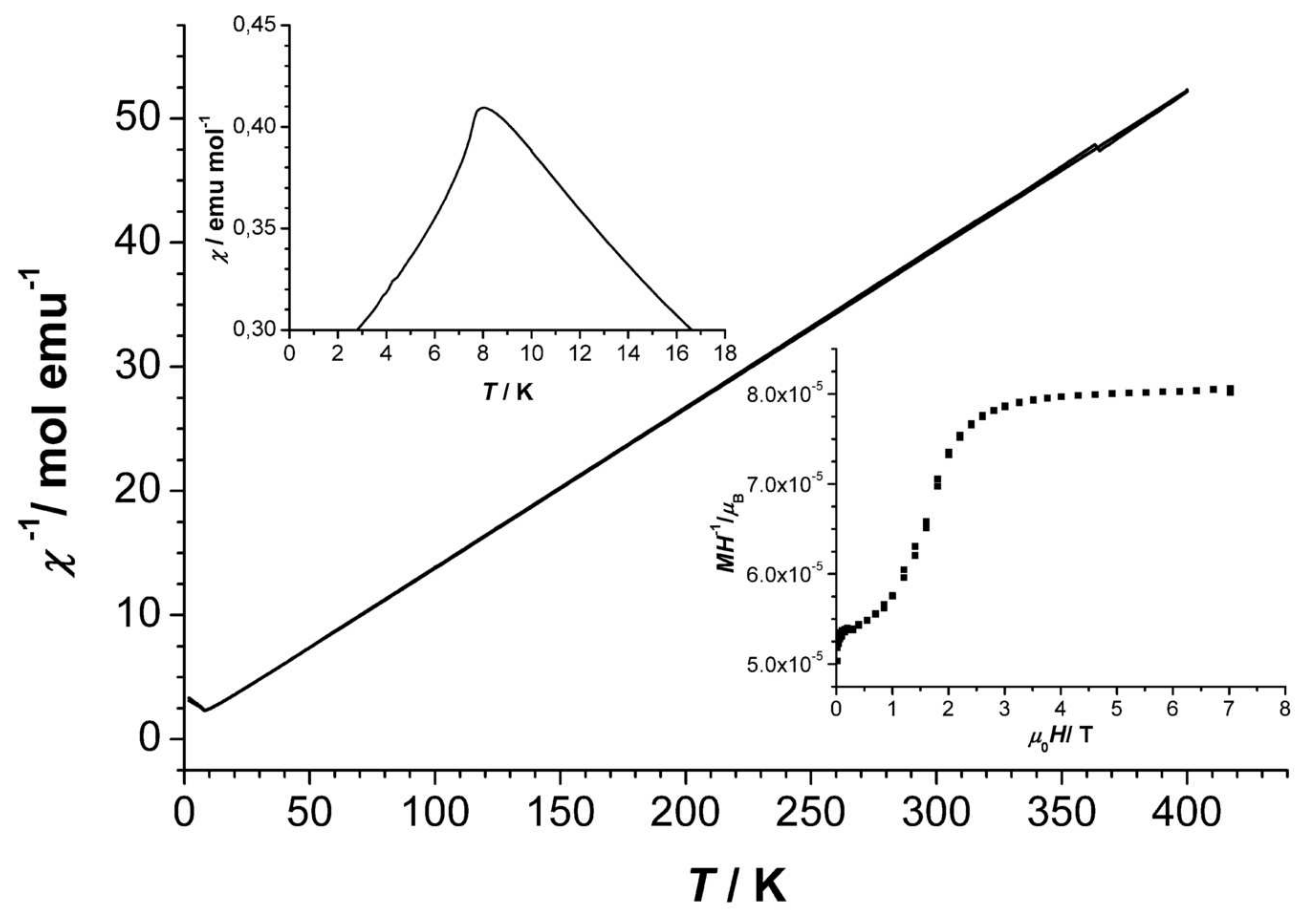

Figure 5: Reciprocal magnetic susceptibility $1 / X$ of $\mathrm{GdS}_{2}$ as function of temperature $T$ in two different external fields $\mu_{0} H(0.1 \mathrm{~T}$ and $1 \mathrm{~T})$. Upper inset: magnetic susceptibility $X(T)$ for $\mu_{0} H=$ $0.01 \mathrm{~T}$ at low temperatures. Lower inset: magnetic susceptibility $X$ as function of external field $\mu_{0} H$ for $\mathrm{T}=1.8 \mathrm{~K}$. See text for discussion.

$57 \times 41 \mathrm{~mm}(600 \times 600 \mathrm{DPI})$ 